\title{
Acquisition of full effector function in vitro paradoxically impairs the in vivo antitumor efficacy of adoptively transferred CD8 ${ }^{+} \mathrm{T}$ cells
}

\author{
Luca Gattinoni, ${ }^{1}$ Christopher A. Klebanoff,1,2 Douglas C. Palmer, ${ }^{1}$ \\ Claudia Wrzesinski, ${ }^{1}$ Keith Kerstann, ${ }^{1}$ Zhiya Yu, ${ }^{1}$ Steven E. Finkelstein, ${ }^{1}$ \\ Marc R. Theoret, ${ }^{1}$ Steven A. Rosenberg, ${ }^{1}$ and Nicholas P. Restifo' \\ ${ }^{1}$ Center for Cancer Research, National Cancer Institute (NCI), NIH, Bethesda, Maryland, USA. \\ ${ }^{2}$ Howard Hughes Medical Institute-NIH Research Scholars Program, Bethesda, Maryland, USA.
}

\begin{abstract}
T cell differentiation is a progressive process characterized by phenotypic and functional changes. By transferring tumor-specific $\mathrm{CD8}^{+} \mathrm{T}$ cells into tumor-bearing mice at various stages of differentiation, we evaluated their efficacy for adoptive immunotherapy. We found that administration of naive and early effector $T$ cells, in combination with active immunization and IL-2, resulted in the eradication of large, established tumors. Despite enhanced in vitro antitumor properties, more-differentiated effector $T$ cells were less effective for in vivo tumor treatment. Several events may underlie this paradoxical phenomenon: (a) downregulation of lymphoid-homing and costimulatory molecules; (b) inability to produce IL-2 and access homeostatic cytokines; and (c) entry into a proapoptotic and replicative senescent state. While the progressive acquisition of terminal effector properties is characterized by pronounced in vitro tumor killing, in vivo $\mathrm{T}$ cell activation, proliferation, and survival are progressively impaired. These findings suggest that the current methodology for selecting $T$ cells for transfer is inadequate and provide new criteria for the generation and the screening of optimal lymphocyte populations for adoptive immunotherapy.
\end{abstract}

\section{Introduction}

Adoptive cell transfer therapy (ACT), the administration of ex vivoactivated and -expanded autologous tumor-reactive T cells, is currently one of the few immunotherapies that can induce objective clinical responses in significant numbers of patients with metastatic solid tumors (1-3). In a previous study, ACT after lymphodepleting conditioning caused objective responses in $46 \%$ of patients with metastatic melanoma refractory to other therapeutic modalities (4). We have now tripled the size of the original study (4), and the objective response rate exceeds $50 \%$, and $11 \%$ of all patients treated are complete responders (5).

There are several theoretical advantages to the use of ACT in treatment of cancer. Tumor-specific $T$ cells can be activated and expanded to large numbers ex vivo, independently of the immunogenic properties of the tumor. Perhaps most important, the functional and phenotypic qualities of $\mathrm{T}$ cells can be selected prior to their adoptive transfer.

Much progress has been made in the understanding of the properties of $\mathrm{T}$ cell subpopulations associated with states of $\mathrm{T}$ cell differentiation in mice and humans, especially those states that are related to the generation of memory $T$ cells capable of protecting against viral challenge (6-9). However, little progress has been made in identifying the characteristics of cell states that are associated with the successful treatment of large, established tumors in mice or in humans.

Nonstandard abbreviations used: ACT, adoptive cell transfer therapy; CCR7, chemokine receptor 7; CM, culture media; hgp 100 $25-33$, human gp 100 $25-33$; IL-7R $\alpha$, IL-7 receptor $\alpha$; KLRG-1, killer cell lectin-like receptor G1; $\beta_{2} \mathrm{~m}^{-1 /}, \beta_{2}$ microglobulin ${ }^{-/}$; rFPhgp100, recombinant fowlpox virus expressing hgp100; rhIL-2, recombinant human IL-2.

Conflict of interest: The authors have declared that no conflict of interest exists.

Citation for this article: J. Clin. Invest. 115:1616-1626 (2005).

doi:10.1172/JCI24480.
Currently, the only criterion applied to selecting cells for adoptive transfer to patients with solid tumors is the ability of antitumor T cells to release IFN- $\gamma$ and kill tumor cells upon coculture $(2,10)$. However, based on a retrospective analysis of ACT in melanoma patients, it is now clear that these criteria alone do not predict in vivo efficacy - despite enhanced in vitro antigen-specific IFN- $\gamma$ release and cytolysis, tumor-specific $\mathrm{CD} 8^{+}$clones did not induce objective clinical responses upon adoptive transfer (10-12).

We sought to determine whether the functional and phenotypic qualities associated with $\mathrm{CD} 8^{+} \mathrm{T}$ cell differentiation affect the ability of tumor-specific $\mathrm{T}$ cells to mediate tumor regression. We tested this hypothesis using $\mathrm{T}$ cells derived from pmel-1 TCR-Tg mice in adoptive transfer experiments (13). The pmel-1 system accurately models the human situation in many important respects. The target antigen, pmel-17, is a highly homologous ortholog of the self/ tumor antigen gp100 that is often targeted in human clinical trials $(14,15)$. In addition, the exogenous administration of high doses of IL-2 and the lymphodepleting conditioning represent other elements shared with our clinical protocols. In contrast to the human situation, in which cells are isolated from cancer patients, we used $\mathrm{CD}^{+} \mathrm{T}$ cells derived from naive non-tumor-bearing mice; however, it is important to note that in the presence of either B16 melanoma or a gp100-nonexpressing irrelevant tumor, pmel-1 T cells remain naive (16). After adoptive transfer, $\mathrm{T}$ cells from tumor-bearing pmel-1 mice are able to eradicate established tumors as well as $\mathrm{T}$ cells derived from naive pmel-1 mice (data not shown). Thus, there is neither activation nor tolerance of these tumor-reactive $T$ cells in the presence of large established tumors - instead, these tumorreactive $T$ cells exist in a state of immunological ignorance (13).

In the current article, we elucidate the $\mathrm{T}$ cell differentiation state (i.e., the specific phenotypic and functional qualities) of cells associated with responses in the ACT setting and clarify the 
A
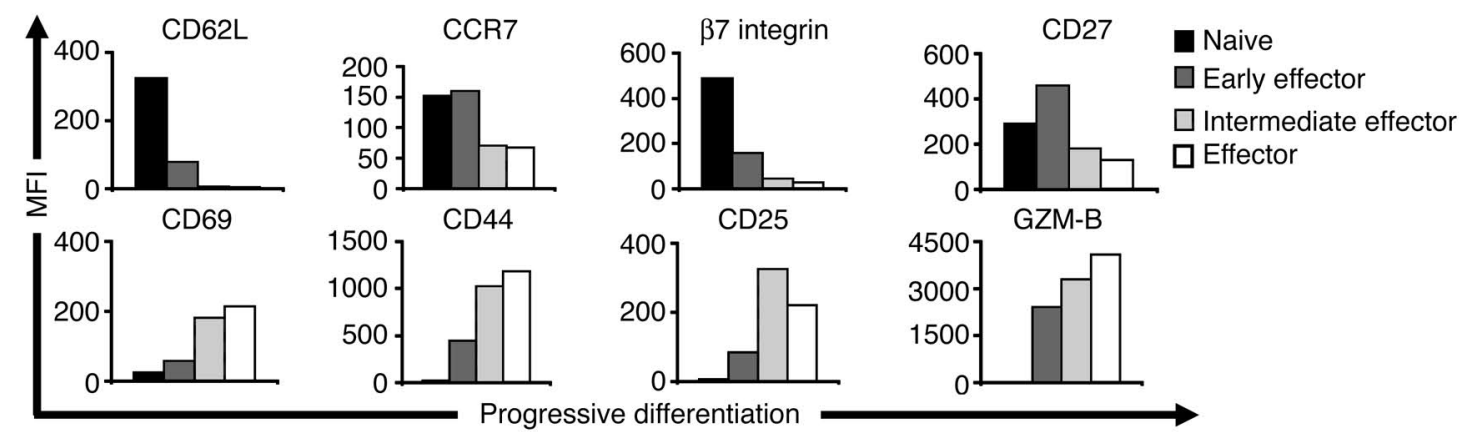

B
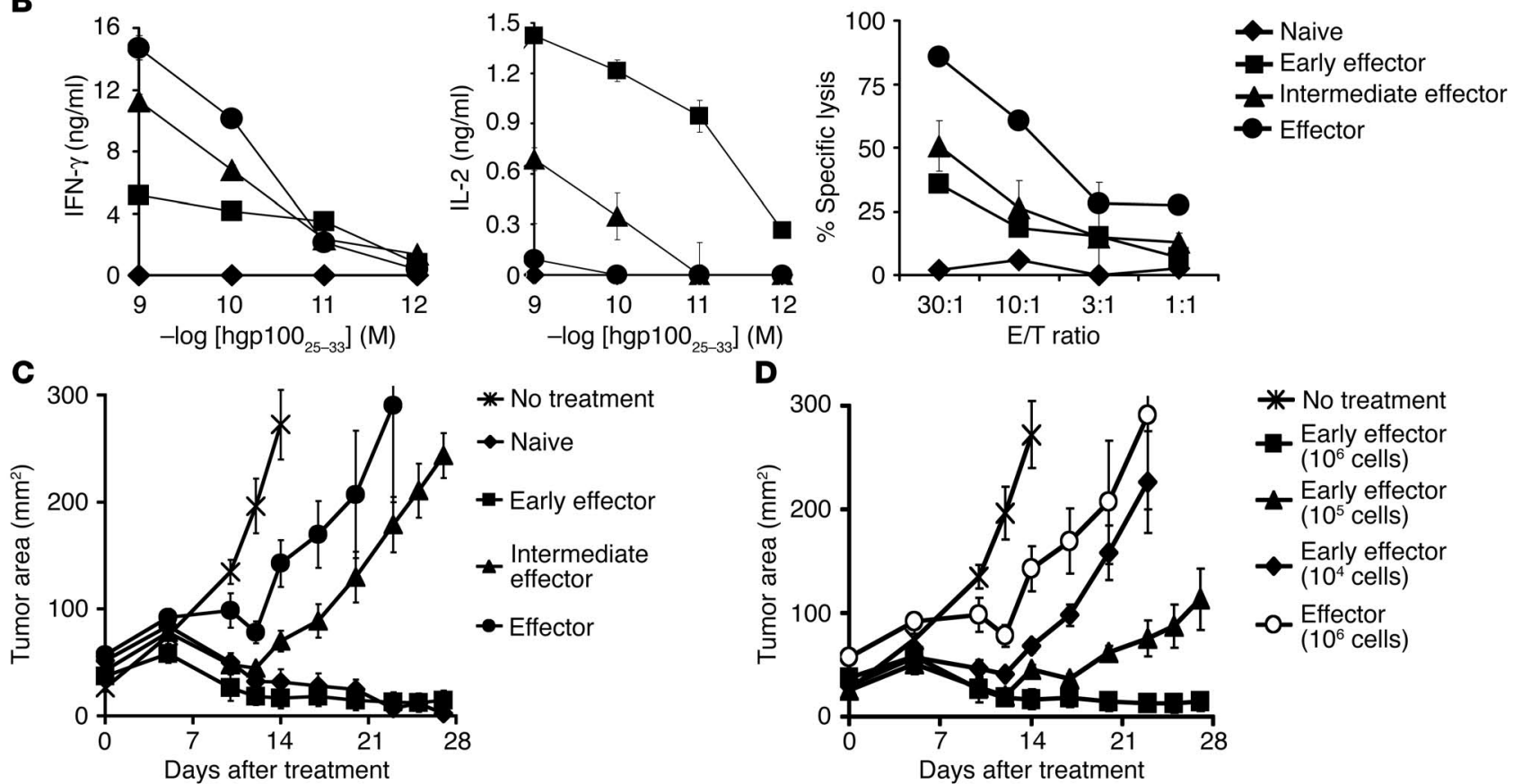

Figure 1

Acquisition of full effector function in vitro impairs antitumor efficacy. Pmel-1 CD8 ${ }^{+} \mathrm{T}$ cells at progressive stages of differentiation were generated using multiple in vitro stimulations with $1 \mu \mathrm{M} \mathrm{hgp} 100_{25-33}$ and $30 \mathrm{IU} / \mathrm{ml}$ of rhIL-2. Seven days following the last stimulation, phenotypic and functional assays were performed. (A) Phenotypic differences in naive and effector subgroups. Flow cytometry analysis for the expression of lymphoid-homing molecules CD62L, CCR7, and $\beta 7$ integrin; costimulatory molecule CD27; activation/effector markers CD69, CD44, CD25, and granzyme-B (GZM-B) on CD8-enriched pmel-1 naive, early effector, intermediate effector, and effector T cells. Mean fluorescence intensity (MFI) values after gating on $\mathrm{CD}^{+}$cells are shown. Data shown are representative of 3 independent experiments. (B) Functional differences in naive and effector subgroups. IFN- $\gamma$ and IL-2 release and cytotoxic assay against hgp $100_{25-33}-$ pulsed MCA-205 targets. MCA-205 cells plus the irrelevant influenza nucleoprotein peptide were used as control. In the cytotoxic assay, values for control target cells (0-14\%) were subtracted. Data shown are representative of 3 independent experiments. (C and D) Differentiation of antitumor T cells is inversely associated with in vivo effectiveness. WT mice bearing 10-day-old established s.c. B16 tumors were sublethally irradiated and left untreated as control or received adoptive transfer of $1 \times 10^{6}$ (when not otherwise indicated) CD8-enriched pmel-1 naive, early effector, intermediate effector, and effector T cells in conjunction with rFPhgp100 vaccination and exogenous rhIL-2 (36 $\mu \mathrm{g}$ per dose). Results for tumor area are the mean of measurements from 5 mice per group $( \pm$ SEM). Data shown are representative of 7 independent experiments.

mechanisms that impair a T cell's ability to cause tumor regression. Finally, we suggest specific solutions to generate more effective antitumor $\mathrm{T}$ cells for the development of experimental human adoptive cell transfer-based therapies.

\section{Results}

Acquisition of terminal effector functions in vitro impairs in vivo antitumor efficacy. To determine whether the differentiation state of $\mathrm{CD}^{+}$ $\mathrm{T}$ cells may affect their ability to mediate tumor regression when adoptively transferred in vivo, we generated pmel- $1 \mathrm{CD}^{+} \mathrm{T}$ cells at progressive stages of differentiation (naive, early effector, intermediate effector, effector). We obtained these cells using multiple in vitro stimulations with antigen and IL-2 (unstimulated, stimulated once, stimulated twice, stimulated 3 times). We then assessed a variety of phenotypic and functional attributes to validate the stage of $\mathrm{CD}^{+} \mathrm{T}$ cell differentiation. After multiple in vitro stimulations, naive pmel-1 cells differentiated into fully mature effector $\mathrm{CD}^{+} \mathrm{T}$ cells, as indicated by the progressive downregulation of CD62L, chemokine receptor 7 (CCR7), $\beta 7$ integrin, and CD27 and the concurrent increase in the levels of CD44, CD69, CD25, 
Table 1

Microarray analysis of early effector and intermediate effector T cells

\section{Genes highly expressed} in early effector cells

Lymphoid-homing

\section{change}

cd62I

ccr7

integrin $\alpha_{\mathrm{E}}$

Costimulatory molecules

cd27

T cell survival/memory generation

il-7r $\alpha$

cd27
E/I, fold change

\section{6}

3.7

3.1
Genes highly expressed in intermediate effector cells

$\begin{array}{ll}\text { Effector } & \mathrm{I} / \mathrm{E}, \\ \text { function } & \text { fold }\end{array}$

$\begin{array}{cc}\text { granzyme A } & 5.1 \\ \text { granzyme B } & 6.0 \\ \text { granzyme C } & 6.0 \\ \text { granzyme D } & 3.5 \\ \text { granzyme } E & 2.9 \\ \text { granzyme } F & 3.9 \\ \text { granzyme G } & 3.1 \\ \text { granzyme K } & 5.0 \\ \text { perforin } & 2.4 \\ \text { fas-ligand } & 2.4 \\ \text { IFN- } & 3.4 \\ \text { eomesodermin } & 4.5 \\ \text { Apoptosis } & \\ \text { bid } & 10.7 \\ \text { bad } & 4.4 \\ \text { fas-ligand } & 2.4 \\ \text { Replicative } & \\ \text { senescence } & \\ \text { klrg-1 } & \\ \text { mrgx } & 2.5\end{array}$

Results shown are the geometric mean of 2 experiments using independently generated sets of cells. Reversing the flourochromes resulted in similar results. $\mathrm{E}$, early effector cells; I, intermediate effector cells. and granzyme-B (Figure 1A). The acquisition of an effector phenotype was associated with an increase in cytolytic activity and IFN- $\gamma$ release but a decrease in IL-2 production (Figure 1B).

We next adoptively transferred these cells into lymphodepleted C57BL/6 WT mice bearing subcutaneous B16 tumors established for 10 days to test their in vivo antitumor functions. Pmel-1 CD8 ${ }^{+}$ $\mathrm{T}$ cells that were naive or at early effector stage, in combination with an altered ligand vaccine and IL-2, were able to effectively treat large, established B16 melanoma. Unexpectedly, despite enhanced antitumor properties in vitro, more-differentiated $\mathrm{T}$ cells were less effective upon adoptive transfer $(P=0.009$; Figure $1 C)$. According to a titration experiment, effector cells were at least 100-fold less effective than early effector cells (Figure 1D). It was surprising that the least effective cells we used had the characteristics that we and others cur-

\section{Figure 2}

Cytofluorometry and Western blot analysis of effective and impaired CD8+ T cells. Pmel-1 CD8+ T cells at progressive stages of differentiation were generated using multiple in vitro stimulations with $1 \mu \mathrm{M}$ hgp $100_{25-33}$ and $30 \mathrm{IU} / \mathrm{ml}$ of rhlL-2. (A) Flow cytometry for the surface expression of IL-7R $\alpha$ and KLRG-1. Results after gating for $\mathrm{CD}^{+}$cells are shown. (B) Detection of BID and its activated, truncated C-terminal cleavage products (tBID) p15 and p13 and BAD by Western blot analysis. rently seek in T cells for use in current ACT-based human trials (2). Specifically IFN- $\gamma$ release and cytotoxicity were negatively correlated with in vivo antitumor efficacy.

Further characterization of in vivo effective and impaired $C D 8^{+}$ $T$ cells. To investigate the mechanisms underlying the lack of antitumor effectiveness of highly differentiated T cells, we extended our characterization of early effector and intermediate effector $\mathrm{T}$ cells using microarray analysis. RNA was extracted from early effector and intermediate effector $T$ cells and indirectly labeled after a single round of linear amplification. The labeled samples were combined and hybridized overnight on a murine 22,000-gene oligonucleotide array. All raw data sets have been deposited, and processed values and complete gene lists are available (GEO series id GSE2348; http://www.ncbi.nlm.nih.gov/geo/).

Microarray analysis confirmed that impaired cells differentially expressed genes associated with highly differentiated effector $\mathrm{T}$ cells. The expression of many genes involved in effector functions such as granzymes, perforin, IFN- $\gamma$, and fas-ligand were strongly upregulated in impaired cells compared with in vivo effective cells (Table 1). Furthermore, intermediate effector cells overexpressed eomesodermin, a transcription factor recently described as a master regulator for $\mathrm{CD}^{+}$effector functions (17). Conversely, early effector cells showed a more naive profile, expressing higher levels of the lymphoid-homing molecules $c d 62 l$, integrin- $\alpha_{E}$, and $c c r 7$, the costimulatory molecule $c d 27$ and $I L-7$ receptor $\alpha$ (il-7r $\alpha)$. However, highly differentiated $\mathrm{T}$ cells overexpressed a number of genes that may prejudice their survival capability, such as the proapoptotic molecules bid, bad, and fas-ligand (18-20). Intermediate effector cells also expressed higher levels of molecules associated with replicative senescence such as killer cell lectin-like receptor $G 1(k \operatorname{lrg} 1)(21,22)$ and the mortality factor $m r g x(23)$, which suggests that the proliferative potential of these cells may be decreased. Microarray data were validated by flow cytometry, Western blot, and functional analyses (Figure1, A and B; Figure 2, A and B). Interestingly, according to the Western blot analysis, it was the truncated, active, C-terminal products of caspase- 3 and -8 cleavage of BID (tBID) that were present at higher levels in impaired cells $(18,20)$. It should be noted that it was the $\mathrm{p} 13$ product - usually a minor form exclusively associated with the mitochondria - that
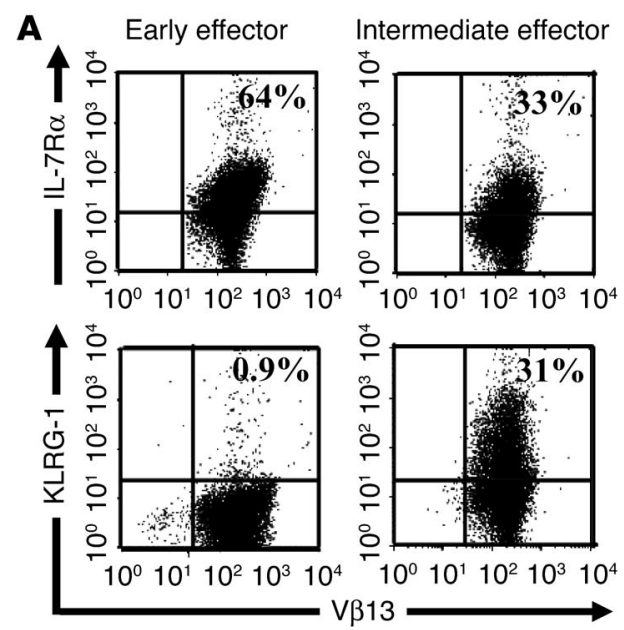

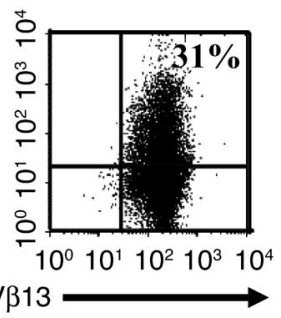

B

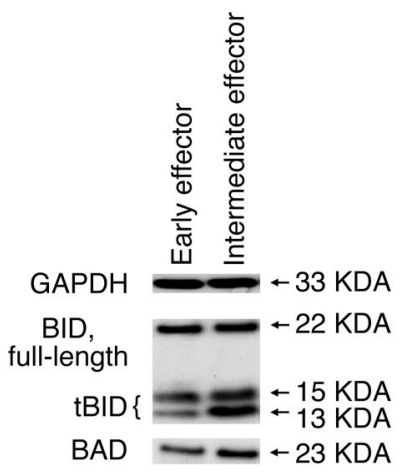


A
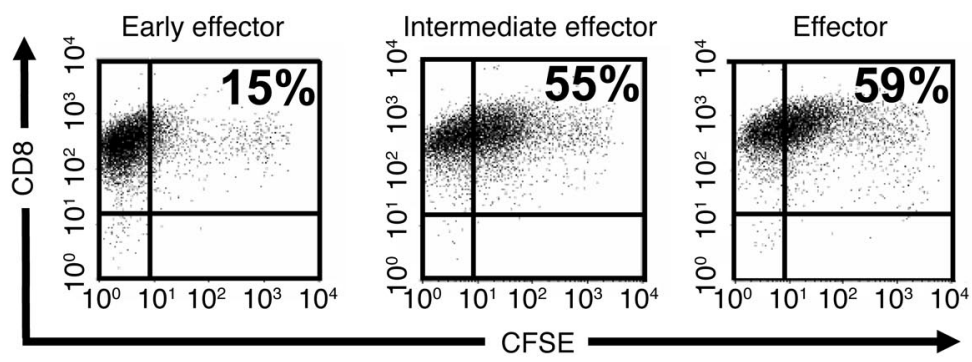

B

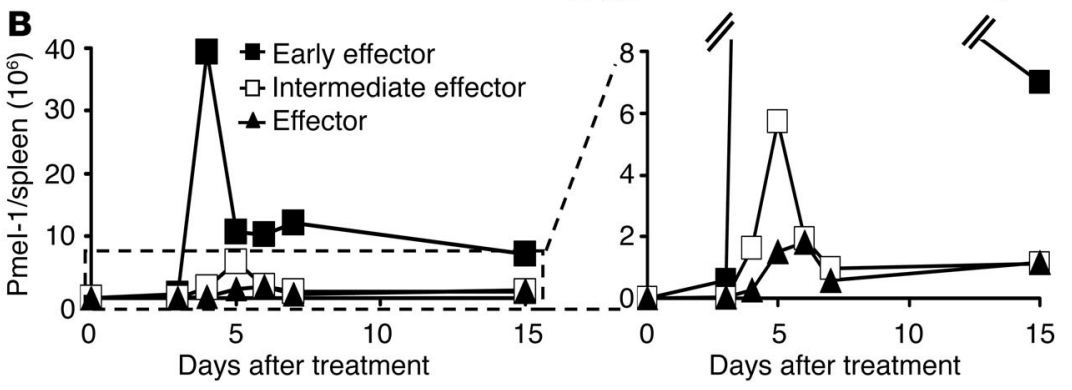

Figure 3

The differentiation state of $\mathrm{CD} 8^{+} \mathrm{T}$ cells is inversely related to their proliferative capacity. Pmel-1 CD8 ${ }^{+} T$ cells at progressive stages of differentiation were generated using multiple in vitro stimulations with $1 \mu \mathrm{M}$ hgp $100_{25-33}$ and $30 \mathrm{IU} / \mathrm{ml}$ of rhlL-2. (A) In vitro proliferation of effector subgroups. Early effector, intermediate effector, and effector T cells were labeled with CFSE and were cultured with $1 \mu \mathrm{M}$ hgp $100_{25-33}$ peptide-pulsed on irradiated splenocytes in the presence of $30 \mathrm{IU} / \mathrm{ml}$ rhlL-2. Cells were harvested after 4 days, and their CFSE content was determined. Results after gating on $\mathrm{V} \beta 13^{+}$population are shown. This experiment was performed twice with similar results. (B) In vivo proliferation of effector subgroups. Absolute numbers of adoptively transferred pmel-1 cells $\left(C D 8^{+} \mathrm{V} \beta 13^{+}\right)$in the spleens of tumor-bearing, sublethally irradiated WT mice. Mice were treated with rFPhgp100, rhlL-2 (36 $\mu \mathrm{g}$ per dose), and $1 \times 10^{6}$ pmel- 1 early effector, intermediate effector, and effector $T$ cells. Data shown are the mean of 2 mice per group. This experiment was performed twice, with similar results.

was strongly elevated ( $>3$-fold by densitometry) in intermediate effector T cells (20). Thus, the Western blot confirmed and further refined the results of the analysis of global gene expression.

T cell differentiation is associated with progressive impairment of proliferative capacity. The analysis of global gene expression suggested that fully differentiated effector T cells may be less "fit" (24) and more proapoptotic. We sought to determine the relative proliferative capacity of effector $\mathrm{T}$ cell subpopulations in vitro and in vivo. We evaluated the proliferative capability in vitro with a CFSE-based assay. Four days after antigen stimulation in IL-2, early effector cells had proliferated vigorously - only $15 \%$ of the starting population failed to dilute the CFSE label to levels comparable to those of unlabeled cells (data not shown). By sharp contrast, $55 \%$ of the intermediate effector and $59 \%$ of the effector T cells failed to fully dilute the label, which indicates that the differentiation state was inversely related to $\mathrm{T}$ cell proliferative capacity (Figure 3A).

To test whether the in vitro findings could predict the proliferative capacity of $\mathrm{T}$ effector subsets upon adoptive transfer, we directly quantified the absolute number of $\mathrm{CD} 8^{+} \mathrm{V} \beta 13^{+}$pmel-1-Tg $\mathrm{T}$ cells at multiple time points in the blood and in the spleen. The differences observed in vivo were more pronounced than those observed in vitro. Each of the effector subsets was transferred $\left(1.0 \times 10^{6}\right)$ with altered peptide ligand vaccine and IL- 2 . The progeny of all effector subgroups reached a peak number between days 4 and 6 after transfer. However, in the spleen alone, we found that $39.5 \times 10^{6}$ progeny derived from early effectors but only $5.7 \times 10^{6}$ and $1.8 \times 10^{6}$ pmel- $1 \mathrm{~T}$ cells derived from intermediate effector and effector cells, respectively (Figure 3B). A similarly pronounced difference was observed in the blood (data not shown). Thus, progressive acquisition of antitumor effector function led to deterioration of the numbers of surviving $T$ cells in vivo.

Further subfractionation of early effector $T$ cells by expression of CD62L identifies $C D 8^{+} T$ cells with superior in vivo antitumor properties. In our experiments using the highly effective/early effector population, we observed significant homogeneity with regard to most differentiation markers. However, in the early effector subpopulation there remained significant heterogeneity in the expression of CD62L, which was lost with further $\mathrm{T}$ cell differentiation and failure of antitumor function in vivo (Figure 1A).

We sought to understand whether CD62L was functionally important or merely a marker of the state of differentiation. We further subfractionated the early effector $\mathrm{T}$ cell population by sorting cells into CD62 $\mathrm{L}^{\text {high }}$ and CD62 $\mathrm{L}^{\text {low }}$ subsets (Figure 4A). The CD62L low population appeared slightly more differentiated on the basis of CD25 and CD69 expression, but all cells in the CD62 $\mathrm{L}^{\text {high }}$ and CD62 $\mathrm{L}^{\text {low }}$ subgroups demonstrated an "antigen-experienced" phenotype. Most phenotypic markers were expressed at a similar level, including CD27, CD44, and IL-7R $\alpha$ (Figure 4B). As KLRG-1 - a sensitive marker for replicative senescence - was virtually absent in both CD62 $\mathrm{L}^{\text {high }}$ and CD62 $\mathrm{L}^{\text {low }}$ subsets, neither of the 2 groups had entered into a senescence state (Figure 4B). Functionally, CD62 L ${ }^{\text {high }}$ and CD62L low subsets showed similar cytolytic activity and IFN- $\gamma$ production. Importantly, no deficit in IL-2 release was seen in either population (Figure 4C). Furthermore, no differences in proliferation were observed when CFSE-labeled CD62 $\mathrm{L}^{\text {high }}$ and CD62 $\mathrm{L}^{\text {low }}$ populations were stimulated in vitro with antigen and IL-2 (Figure 4D).

Despite these similarities, when transferred in conjunction with an altered ligand vaccine and IL-2, the CD62 $\mathrm{L}^{\text {high }}$ subset had superior antitumor function $(P=0.009$; Figure $5 \mathrm{~A})$. This was associated with pronounced in vivo expansion of the CD62 $\mathrm{L}^{\text {high }}$ subset in the spleen (Figure 5B). Similar results were observed in tumor (Figure 5C) and blood (data not shown). Thus, these differences were not the result of selective accumulation in lymphoid tissues mediated by CD62L. However, no statistical difference was observed when high or low subsets were transferred in the absence of vaccination $(P>0.05$; Figure 5A). To definitively assess whether CD62L was functionally important, we crossed pmel-1-Tg mice with CD62 $\mathrm{L}^{-/}$ mice. Splenocytes from pmel-1-CD62 $\mathrm{L}^{-/}$and age-matched pmel-1CD $62 \mathrm{~L}^{+/+}$mice possessed similar phenotypic and functional attributes in vitro after activation (data not shown). By contrast, when adoptively transferred in WT mice bearing B16 tumors established for 10 days, pmel-1-CD62 $\mathrm{L}^{-/-}$cells were less effective in treating tumors compared with pmel-1-CD62 $\mathrm{L}^{+/+}(P=0.014$; Figure 5D). Thus, CD62L not only represents a marker of $\mathrm{T}$ cell differentiation state but also plays an important functional role in this adoptive immunotherapy model of large, established tumors. 
A
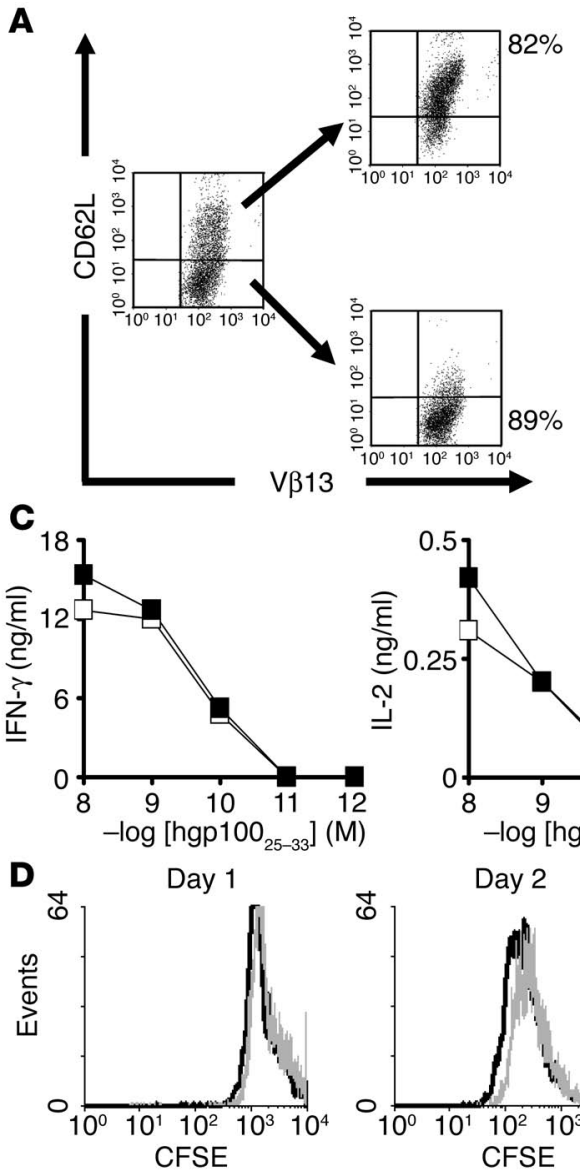
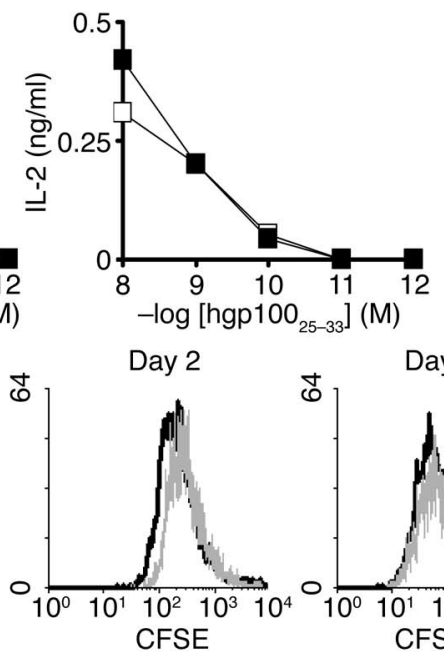

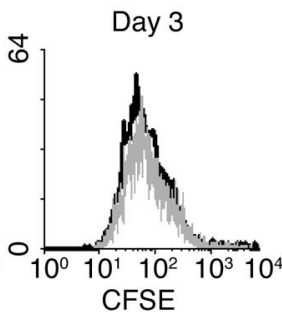

B
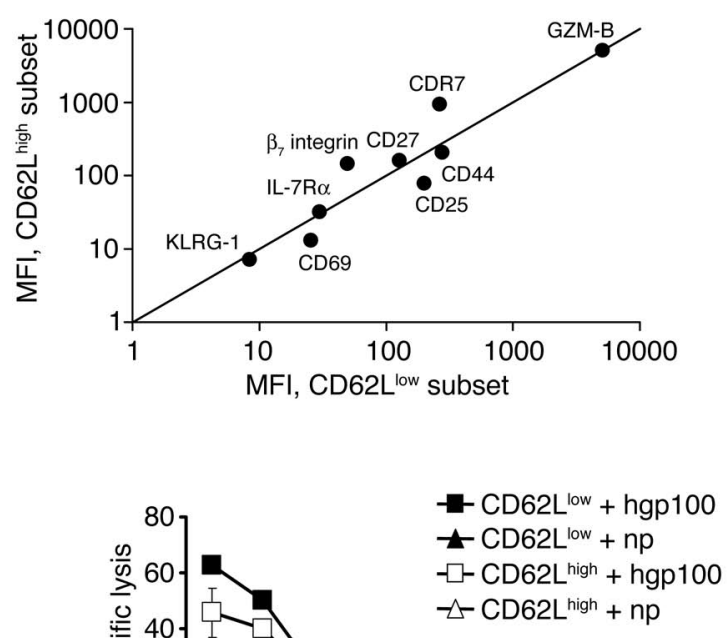

Figure 4

Subfractionated CD62L high and CD62 L low early effector cells possess similar properties in vitro. (A and B) Phenotypic characterization of CD62 ${ }^{\text {high }}$ and CD62 L ${ }^{\text {low }}$ subsets. Five days after the initial stimulation with antigen and IL-2, CD62 $L^{\text {high }}$ and CD62L low populations were sorted by MACS CD62L-positive selection column and analyzed by flow cytometry on day 6 for the expression of IL-7R $\alpha$; lymphoid-homing molecules $\beta 7$ integrin and CCR7; the costimulatory molecule CD27; activation/effector markers CD44, CD69, CD25, and granzyme-B; and the senescence marker KLRG-1. MFI values after gating on $\mathrm{CD}^{+} \mathrm{V} \beta 13^{+}$cells are shown. The MFI was determined for all groups at the same time under the same cytoflourometric settings using the same reagents and isotype-matched controls. Data shown are representative of 2 independent experiments. (C)

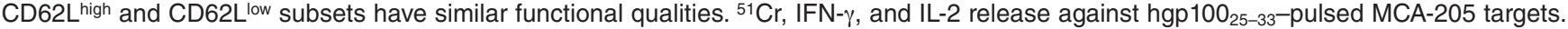
MCA-205 cells plus influenza nucleoprotein peptide (np) were used as control. Where error bars are not visible, it is because they are obscured by the symbols used. Data shown are representative of 2 independent experiments. (D) CD62L high and CD62L low subsets have similar proliferative capacity. CD62 Ligh and CD62L low cells were labeled with CFSE and were cultured with hgp $100_{25-33}$ peptide-pulsed on irradiated splenocytes in the presence of $30 \mathrm{IU} / \mathrm{ml}$ of rhlL-2. Cells were harvested from day 1 to day 4 , and their CFSE content was determined. Results after gating on $\mathrm{CD}^{+} \mathrm{V} \beta 13^{+}$population are shown. This experiment was performed twice, with similar results.

Tumor antigen presentation by BM-derived APCs is required for successful tumor treatment. Differences between $C D 62 \mathrm{~L}^{\text {high }}$ and CD62 $\mathrm{L}^{\text {low }}$ population were observed only in the presence of vaccination. Consistent with findings of others $(25,26)$, we found that $\mathrm{CD} 62 \mathrm{~L}^{\text {high }} \mathrm{T}$ cells preferentially homed to lymph nodes. This finding was obtained using confocal laser scanning microscopy (data not shown). Taken together, these data suggested that the lymphoid homing of CD62 $\mathrm{L}^{\text {high }} \mathrm{T}$ cells could result in a more effective interaction with APCs.

In order to evaluate the role of APCs in this model, we generated a variety of chimeras by transferring BM cells from $\beta_{2}$ microglobulin ${ }^{-/}\left(\beta_{2} \mathrm{~m}^{-/-}\right)$and from WT mice into lethally irradiated $\beta_{2} \mathrm{~m}^{-/-}$and WT mice (Figure 6A). Chimeras were analyzed for reconstitution with the appropriate donor marrow after 8 weeks (data not shown) and subsequently challenged subcuta- neously with B16 melanoma. Adoptive transfer of early effector cells, in combination with an altered ligand vaccine and exogenous IL-2, was unable to treat B16 tumors in $\beta_{2} \mathrm{~m}^{-/-} / \beta_{2} \mathrm{~m}^{-/-}$chimeras (Figure 6B). As previously reported in studies using other models (27), self/tumor antigen presentation by B16 melanoma was insufficient to efficiently stimulate adoptively transferred $\mathrm{T}$ cells, and no significant differences in tumor growth were seen compared with untreated mice $(P>0.05)$. However, transfer of $\mathrm{CD}^{+} \mathrm{T}$ cells into $\beta_{2} \mathrm{~m}^{-/-}$mice that had been engrafted with $\mathrm{BM}$ cells derived from WT mice treated B16 melanoma as efficiently as did pmel-1 cells adoptively administered to WT/WT chimeras $(P>0.05$; Figure $6 \mathrm{D})$. Tumor antigen presentation by BM-derived APCs (presumably professional APCs) appear to be critical for successful treatment: adoptively transferred $T$ cells in vivo activated by parenchymal cells, in $\beta_{2} \mathrm{~m}^{-/-} / \mathrm{WT}$ chimeras, were 

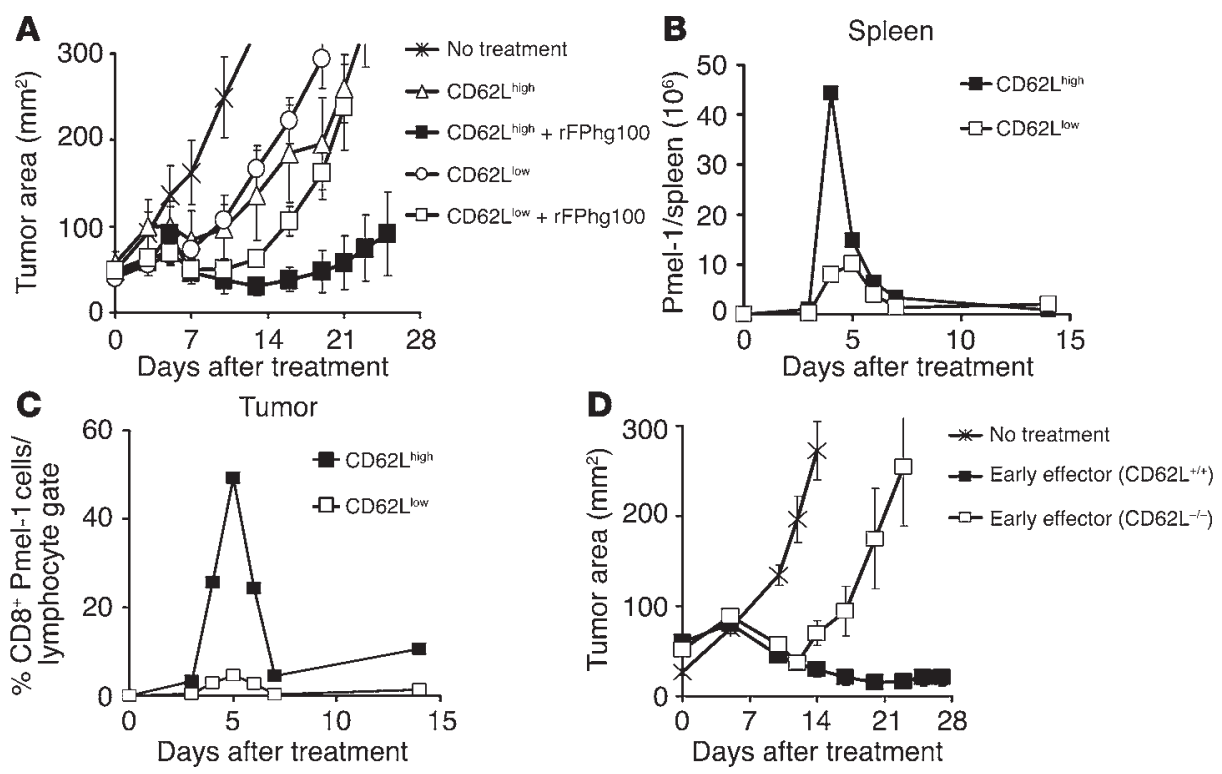

\section{Figure 5}

CD62L-selectin identifies CD8 ${ }^{+} \mathrm{T}$ cells with superior in vivo antitumor properties. (A) CD62L high subset possesses superior in vivo antitumor properties. WT mice bearing 10-day-old established subcutaneous B16 tumors were sublethally irradiated and left untreated as control or received adoptive transfer of $1 \times 10^{6}$ of pmel-1 CD62 Ligh or CD62L low cells with exogenous rhlL-2 (36 $\mu \mathrm{g}$ per dose) with or without $\mathrm{rFPhgp} 100$ vaccination. Results for tumor area are the mean of measurements from 5 mice per group ( \pm SEM). Data shown are representative of 3 independent experiments. (B and C) CD62L high subset expands vigorously in vivo. (B) Absolute numbers of adoptively transferred CD8 ${ }^{+}$pmel-1cells in the spleen of tumor-bearing, sublethally irradiated WT mice. Mice were treated with FPhgp100, rhlL-2 (36 $\mu \mathrm{g}$ per dose), and $1 \times 10^{6}$ of pmel-1 CD62L high or CD62L low cells. Data shown are the mean of 2 mice per group. This experiment was performed twice, with similar results. (C) Percentage of CD8 ${ }^{+}$pmel1cells in the tumor. Mice were treated with FPhgp100, rhIL-2 (36 $\mu \mathrm{g}$ per dose), and $1 \times 10^{6}$ of pmel-1 CD62L high Ly5.1 or CD62L lowThy1.1 cells. Data shown are the mean of 2 mice per group. This experiment was performed twice with similar results. (D) CD62L expression is required to maximize the antitumor efficacy of adoptively transferred T cells. WT mice bearing 10-day-old established s.c. B16 tumors were sublethally irradiated and left untreated as control or received adoptive transfer of $1 \times 10^{6}$ one-weekcultured pmel-1 CD62L $\mathrm{L}^{+/+}$cells or pmel-1 $\mathrm{CD} 2 \mathrm{~L}^{-/}$cells in conjunction with rFPhgp100 vaccination and exogenous rhIL-2 (36 $\mu \mathrm{g}$ per dose). Tumor area results are the mean of measurements from 5 mice per group $( \pm$ SEM). Data shown are representative of 3 independent experiments.

less effective in controlling tumor growth $(P=0.016$; Figure $6 \mathrm{C})$. Thus, our findings suggest that in lymphoid tissues, adoptively transferred T cells utilize CD62L to target professional APCs expressing antigen as a result of the vaccination and that the downregulation of CD62L, due to progressive differentiation, impairs their in vivo activation, their proliferation, and consequently their antitumor activity.

IL-15 uncouples $T$ cell proliferation from differentiation and preserves antitumor efficacy in vivo. Results here indicate that the optimal $\mathrm{T}$ cell populations for ACT are early effector cells that retain high levels of lymphoid-homing molecules. These findings raise a crucial clinical problem. Current successful ACT-based immunotherapies inevitably start from low precursor frequencies of tumor-specific $\mathrm{T}$ cells. These $\mathrm{T}$ cells are currently activated and expanded to clinically therapeutic numbers using IL-2 $(2,10)$. During this expansion, cells inexorably differentiate and lose lymphoid-homing molecules (28). Although $\mathrm{T}$ cells that possess such characteristics can cause objective clinical responses in a significant number of patients $(4,5)$, and can suboptimally treat established tumors in mice, there is an urgent need to improve these results.
We and others have previously reported that splenocytes primed in the presence of IL-15 for 7 days polarized to a less-differentiated $\mathrm{CD}^{+} \mathrm{T}$ cell population that retained high levels of $\mathrm{CD} 62 \mathrm{~L}$ and CCR7 $(26,29,30)$. Here we have extended these findings by testing the ability of IL- 15 to sustain the growth of large numbers of $\mathrm{T}$ cells through multiple restimulations. After 14 days in culture, cells grown in either IL-2 or IL-15 proliferated extensively, undergoing a 1,000-fold expansion (Figure 7A). While the CD62L marker was virtually absent on $\mathrm{T}$ cells grown in IL-2 $(0.2 \%)$, significant numbers of T cells cultured in IL-15 (48\%) retained the expression of $\mathrm{CD} 62 \mathrm{~L}$ (Figure 7B). This resulted in the generation of a $\mathrm{T}$ cell population that was significantly more effective even when used at limiting doses of $1 \times 10^{6}$ cells $(P=0.009$, IL-15 vs. IL-2, day 14 ; $P=0.02$, IL-15 vs. IL-2, day 21) (Figure 7C). Enhanced tumor responses were associated with increased proliferation of IL-15-cultured cells upon adoptive transfer (data not shown). Interestingly, there was a statistically significant inverse correlation between the state of differentiation, as a measured by $\mathrm{CD} 62 \mathrm{~L}$ expression of transferred $\mathrm{T}$ cells, and tumor growth $(P<0.001$; Figure $7 \mathrm{D})$. These data suggest that the use of IL-15 instead of IL-2 could result in significant expansion of $\mathrm{T}$ cells while delaying the acquisition of a detrimental effector state.

\section{Discussion}

$\mathrm{T}$ cells used for current adoptive immunotherapy trials are selected for their capacity to produce high levels of IFN- $\gamma$ and for their ability to efficiently and specifically lyse relevant target cells $(2,10)$. However, we have found that $\mathrm{CD} 8^{+} \mathrm{T}$ cells that acquire complete effector properties and exhibit increased antitumor reactivity in vitro are less effective at triggering tumor regressions and cures in vivo. In addition, as discussed in detail below, emerging data from our human clinical trials support the hypothesis that less-differentiated $\mathrm{T}$ cells are more therapeutically effective upon adoptive transfer. These findings may appear paradoxical but can be resolved by a summary of our results represented diagrammatically in Figure 8.

After adoptive transfer, several events must occur for $\mathrm{T}$ cells to cause the regression of established tumors. (a) $\mathrm{T}$ cells must be activated in vivo through antigen-specific vaccination. (b) They must then vigorously expand to levels capable of causing the destruction of significant tumor burdens. (c) Finally, antitumor T cells must 


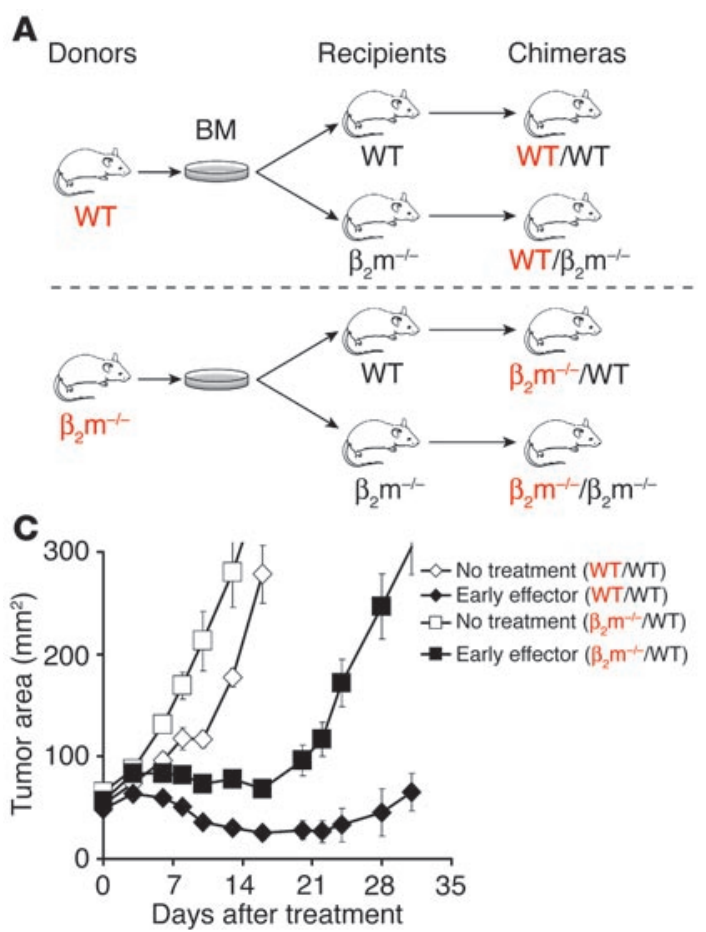

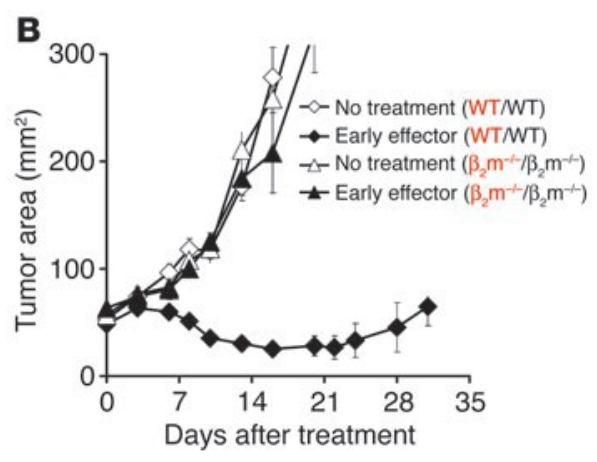

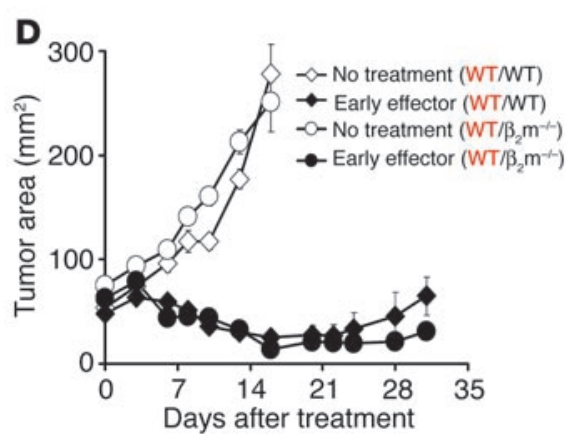

\section{Figure 6}

Antigen presentation by BMderived APCs is critical for tumor treatment. (A) Generation of BM chimeras. We generated chimeras by transferring $5 \times 10^{6} \mathrm{BM}$ cells from $\beta_{2} \mathrm{~m}^{--}$and WT mice into lethally irradiated WT or $\beta_{2} \mathrm{~m}^{-/-}$ mice. (B-D) Results from BM chimeras indicate that BM-derived APCs expressing MHC class I are required for tumor treatment. Chimeras bearing 10-day-old established s.c. B16 tumors were sublethally irradiated and left untreated as controls or received adoptive transfer of $1 \times 10^{6}$ pmel1 cells cultured for 1 week in conjunction with rFPhgp100 vaccination and exogenous rhlL-2 (36 $\mu \mathrm{g}$ per dose). Results for tumor area are the mean of measurements from 5 mice per group ( \pm SEM). Data shown are representative of 2 independent experiments. survive long enough to complete the eradication of all tumor cells (13). In the present work, we found that the progressive differentiation of $\mathrm{T}$ cells to a terminal differentiated effector stage results in a series of phenotypic and functional changes that make them less "fit" to perform these functions.

We previously reported that antigen-specific vaccination using an altered peptide ligand is required to eradicate large, established B16 melanoma (13). Here, we extend these findings by determining that the deprivation of a productive interaction of $\mathrm{T}$ cells with BM-derived APCs (presumably professional APCs) diminishes the therapeutic impact of $\mathrm{T}$ cells. Interestingly, priming $\mathrm{T}$ cells ex vivo does not abrogate the requirement for stimulation by "professional" APCs. In addition, the expression of lymphoid-homing and costimulatory molecules on the surfaces of highly effective T cells provides further evidence that, to be fully therapeutic, adoptively transferred $\mathrm{CD}^{+} \mathrm{T}$ cells must home to secondary lymphoid tissue where they interact effectively with professional APCs. We cannot exclude the possibility that homing to lymph nodes would not be required in the presence of more-immunogenic tumors. Terminally differentiated $\mathrm{T}$ cells may have potent antitumor activity directly on tumor cells after infusion, as activation in lymph nodes may be unnecessary. Our results are consistent with the report that in preventive infectious models, the adoptive transfer of "central memory" CD8 ${ }^{+} \mathrm{T}$ cells that possess enhanced lymphoid-homing properties and higher levels of the costimulatory molecule CD27 provides superior immunity compared with the transfer of CD62 L-CCR7CD27- "effector memory" $T$ cell populations (31). Some authors have reported that the adoptive transfer of CD62 $\mathrm{L}^{\text {low }} \mathrm{T}$ cells provides enhanced tumor treatment (32). However, these polyclonal cells derived from tumor-draining lymph node were selected from an open $\mathrm{T}$ cell repertoire only on the basis of CD62L expression. Thus, it is likely that a CD62 $\mathrm{L}^{\text {low }}$ population is relatively enriched for tumor-reactive $\mathrm{T}$ cells compared with the naive, CD62 $\mathrm{L}^{\text {high }}$ population that has not been stimulated by exposure to tumor.
Although CD62L homing to lymphoid tissues, and the consequent ability of $\mathrm{T}$ cells to be properly activated by professional APCs, is important, it is clearly not the only mechanism underlying the differences in $T$ cell efficacy after adoptive transfer. Neither intermediate effector cells nor effector cells expressed CD62L, but the intermediate effector populations were reproducibly more efficient than effector cells. Enhanced efficacy was associated with greater proliferation and survival in vivo.

Recent findings indicate that costimulatory interaction of CD27 and CD70 can result in prolonged expansion, survival, and memory differentiation of activated $\mathrm{CD}^{+} \mathrm{T}$ cells $(7,33-36)$. These findings suggest that the downregulation of CD27 that accompanies progressive $T$ cell differentiation might contribute to the observed impairment of $\mathrm{CD}^{+} \mathrm{T}$ cell expansion and survival after adoptive transfer.

Because recombinant IL-2 is provided both in the ex vivo expansion of antitumor $\mathrm{CD}^{+} \mathrm{T}$ cells and immediately after their adoptive transfer, T cells may undergo apoptosis upon IL-2 withdrawal (37). Thus, the capacity of T cells to produce their own IL-2 may allow them to survive and expand. In our model, only early effector $\mathrm{CD}^{+} \mathrm{T}$ cells could produce significant levels of IL-2. Naive cells acquire this capability upon antigen stimulation. Cotransfer of $\mathrm{CD} 4{ }^{+} \mathrm{CD} 25^{-}$helper cells, as a natural source of IL-2, may be helpful for the persistence and effectiveness of adoptive T cells (38).

Homeostatic cytokines are important for the survival of $\mathrm{T}$ cells. For example, IL-7 has been shown to be critical for the generation and survival of memory $\mathrm{CD}^{+} \mathrm{T}$ cells, and IL-7R $\alpha$ may identify effector $\mathrm{CD}^{+} \mathrm{T}$ cells that become long-lived memory cells (39-42). Thus, the progressive downregulation of IL-7R $\alpha$ associated with $\mathrm{T}$ cell differentiation may be detrimental to their survival. Similarly, IL-15 plays a supportive role in survival and proliferation of adoptively transferred T cells (40,43-45). We have recently reported that endogenous IL-15 enhances the antitumor efficacy of adoptively transferred $\mathrm{CD}^{+} \mathrm{T}$ cells (29). IL-15 appeared to be presented to 

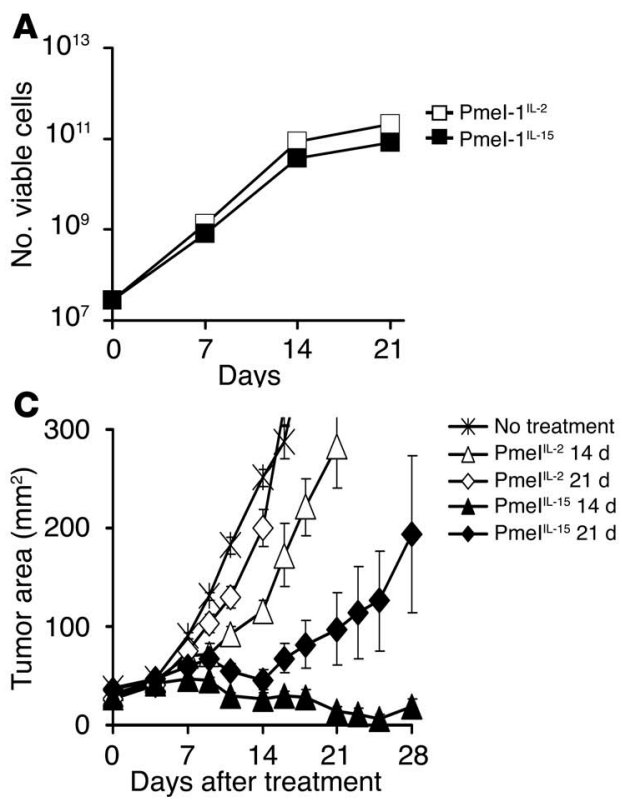

D
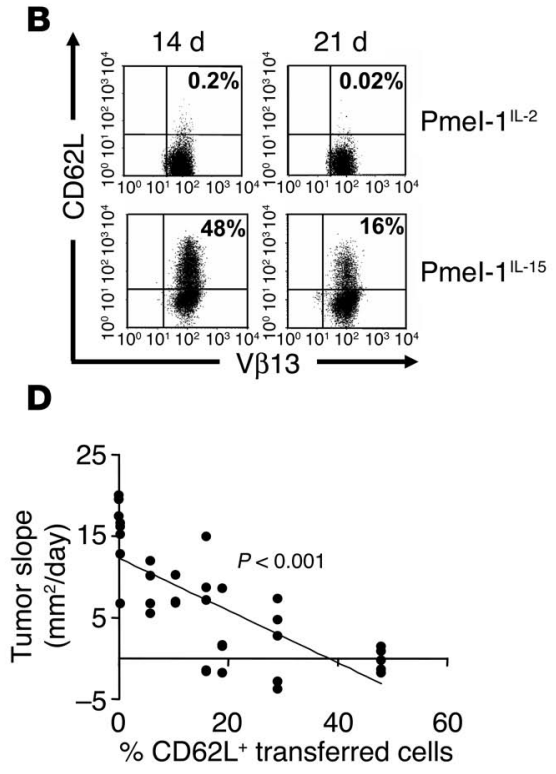

Figure 7

IL-15 uncouples T cell proliferation from differentiation and preserves antitumor efficacy in vivo. Pmel-1 splenocytes were cultured and restimulated weekly in the presence of $1 \mu \mathrm{M}$ hgp $100_{25-33}$ and CM containing $30 \mathrm{UI} / \mathrm{ml}$ of rhlL-2 (Pmel-1 $1^{\mathrm{LL}-2}$ ) or $10 \mathrm{ng} / \mathrm{mL}$ rhlL-15 (Pmel-1 $\left.{ }^{\mathrm{lL}-15}\right)$. (A) T cells expand similarly in media containing IL-2 and IL-15. Pmel-1 $1^{\mathrm{LL}-2}$ and pmel-1/L-15 cells were enumerated using trypan blue exclusion at indicated time points. Data shown are representative of 2 independent experiments. (B) IL-15 preserves the expression of lymphoid-homing molecules after multiple in vitro stimulations. Flow cytometry analysis for the expression of the lymphoidhoming molecule CD62L on pmel-1 $1^{\mathrm{LL}-2}$ and pmel-1 $1^{\mathrm{LL}-15}$ after 14 and 21 days of culture. Results after gating for $\mathrm{CD}^{+}$cells are shown. Data are representative of 2 independent experiments. (C) IL-15 preserves in vivo antitumor efficacy of $\mathrm{T}$ cells after multiple in vitro stimulations. WT mice bearing 10-day-old established subcutaneous B16 tumors were sublethally irradiated and left untreated as control or received adoptive transfer of $1 \times 10^{6}$ pmel-1/L-2 or pmel-1/L-15 cells cultured for 14 and 21 days in conjunction with rFPhgp100 vaccination and exogenous rhIL-2 (36 $\mu \mathrm{g}$ per dose). Tumor area results are the mean of measurements from 5 mice per group $( \pm$ SEM). Data shown are representative of 2 independent experiments. (D) Correlation between CD62L expression on adoptively transferred T cells and slope of tumor growth curve. Results were pooled from 2 independent experiments.

$\mathrm{CD}^{+} \mathrm{T}$ cells in trans by APCs $(46,47)$. Thus, $\mathrm{CD}^{+} \mathrm{T}$ cell trafficking to lymphoid tissues and subsequent interaction with professional APCs may be pivotal not only for in vivo antigen vaccination but also for better access to this homeostatic cytokine.

Induction of apoptosis of activated effector $\mathrm{CD}^{+} \mathrm{T}$ cells is required to maintain lymphoid homeostasis and to prevent the development of autoimmune manifestations and lymphoid neoplasia, but apoptosis after adoptive transfer is clearly undesirable. We consistently found that less therapeutically effective/highly differentiated $\mathrm{T}$ cells overexpressed molecules critically involved in activation-induced cell death, such as Fas ligand. We also found that the molecules involved in activated $\mathrm{T}$ cell-autonomous death, such as the BH3-only proteins $\operatorname{BID}$ and $\operatorname{BAD}(18,19)$, were overexpressed in impaired effector $\mathrm{T}$ cells.

Replicative senescence is the ultimate fate of all somatic cells, including $\mathrm{T}$ cells. In both mice and humans, KLRG-1 identifies antigen-experienced $\mathrm{T}$ cells with an effector/effector memory phenotype that are severely impaired in their proliferative capacity but can perform full effector functions $(21,22)$. Similarly, terminally differentiated pmel-1 cells expressed high levels of KLRG-1 and consistently had reduced replicative capacity.
Although it is possible that these results are specific to self/tumor antigens as well to this particular model, the finding that more-differentiated cells, with superior in vitro antitumor properties, are less capable of mediating tumor regression upon adoptive transfer may be highly relevant to the immunotherapy of cancer patients. In current techniques $(2,10)$, tumor-specific $\mathrm{CD}^{+}$ $\mathrm{T}$ cells generated ex vivo for ACT are generally CD62L-CCR7- effector/effector memory T cells (28). However, within this population, the degree of differentiation can be discriminated on the basis of the expression of the costimulatory molecules CD28 and CD27 and T cell senescence markers KLRG-1 and CD57 and telomere length. The in vivo persistence of $\mathrm{T}$ cells following adoptive transfer significantly correlated with clinical responses in a study carried out on a panel of 25 patients (48). Interestingly, phenotypic and functional analyses on a single responding patient indicated that the fractions of transferred cells that persisted were phenotypically less-differentiated $\left(\mathrm{CD} 45 \mathrm{RO}^{+} \mathrm{CD} 27^{+} \mathrm{CD} 28^{+} \mathrm{CD} 57^{-} \mathrm{KLRG}^{-} \mathbf{1}^{-}\right)$ clonotypes (unpublished observations). However, the most consistent finding that is emerging from the study of T cell clonotypes after adoptive transfer regards the length of telomeres $-\mathrm{T}$ cells with longer telomeres persisted and mediated tumor regression, while cells possessing very short telomeres rapidly disappeared after transfer (unpublished observations). These observations are now being extended using large cohorts of patients.

The idea that highly differentiated $\mathrm{T}$ cells are suboptimal to confer immunity is also supported by recent data from HIV patients. The incidence of IFN- $\gamma^{+}$perforin ${ }^{\text {high }} \mathrm{HIV}$-specific $\mathrm{CD}^{+} \mathrm{T}$ cells has been reported to correlate with HIV-1 disease progression $(49,50)$. In addition, HIV long-term nonprogressors were associated with HIV-specific $\mathrm{CD}^{+} \mathrm{T}$ cells characterized by less-differentiated phenotype $\left(\mathrm{CD} 45 \mathrm{RO}^{+} / \mathrm{CD} 7^{+} / \mathrm{CD} 28^{+}\right)$and high proliferative capacity (51).

We and others have found that highly tumor-reactive $\mathrm{T}$ cell clones did not cause objective regressions of cancer (10-12). Based on the data presented here, it seems clear that clones represent terminally differentiated $\mathrm{CD}^{+} \mathrm{T}$ cells with strong effector functions. These T cells, however, have exhausted their proliferative and survival capabilities - $\mathrm{T}$ cell clones rapidly disappeared after adoptive transfer (10-12). In contrast, adoptively transferred $\mathrm{T}$ cell clones can prevent complications from cytomegalovirus infections in BM-transplanted patients (52). This could be related to the preventive nature of the treatment, which undoubtedly requires fewer cells; the repeated administration of $\mathrm{T}$ cell clones; or the strong immunogenicity of the antigen.

Our work suggests that the current practice of using IFN- $\gamma$ release or cytolysis $(2,10)$ alone to select $T$ cells for transfer could be misleading because it results in the selection of highly differentiated cells 


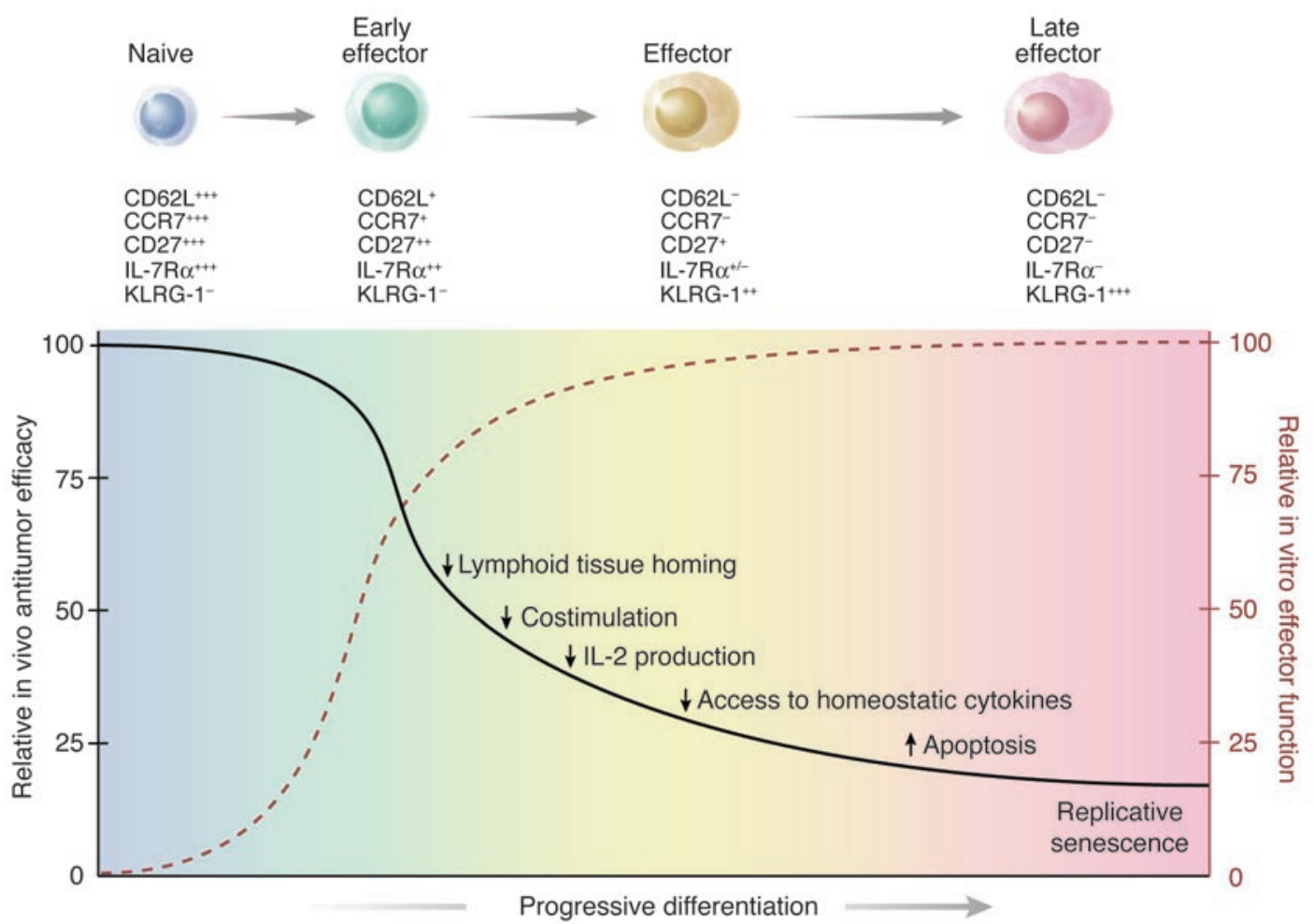

\section{Figure 8}

A schematic illustration summarizing results indicating the inverse relationship of in vitro and in vivo effector functions of adoptively transferred naive and effector $T$ cell subsets. After primary antigen stimulation, naive $C D 8^{+} T$ cells proliferate and progressively differentiate into terminally differentiated effector T cells. Phenotypic and functional changes characterize the differentiation process. The gradual acquisition of complete effector functions (dashed red line) is associated with the progressive inability of T cells to cause tumor regression upon adoptive transfer (black line). Such mechanisms initially involve the downregulation of lymphoid-homing and costimulatory molecules, which results in a poor in vivo activation of T cells. Other mechanisms occur later and include the inability to produce IL-2 and access homeostatic cytokines, the imbalance of proapoptotic and anti-apoptotic signals, and the acquisition of a state of replicative senescence. +, low expression; ++, intermediate expression; +++, high expression.

with decreased proliferative and survival capabilities. We propose that in addition to the usual functional assays, phenotypic analyses and the evaluation of the length of telomeres can be used to identify less-differentiated/more effective $T$ cells for adoptive transfer.

Our results also raise questions about the optimal strategy for the in vitro generation of Tlymphocytes for adoptive transfer - the mere generation of large numbers of highly differentiated $T$ cells for adoptive transfer is insufficient to trigger tumor regression. Cytokines, acting in concert with signals through the TCR, can have differential effects on $\mathrm{T}$ cell differentiation and proliferation (24). High doses of IL-2 have been used to obtain large numbers (up to $10^{11}$ cells) of tumor-reactive T cells for adoptive transfer, but $\mathrm{T}$ cells rapidly differentiate under this condition. In contrast, IL-15 uncouples differentiation from proliferation, enabling the generation of large numbers of less-differentiated/more effective T cells.

These findings are now being applied to current clinical efforts in the treatment of established tumors and may be useful in the treatment of established infectious diseases, including HIV and chronic hepatitis.

\section{Methods}

Mice and tumor lines. Pmel-1 TCR-Tg mice (13) were crossed with C57BL/6 Ly-5.1-Tg, C57BL/6 Thy1.1-Tg, and C57BL/6 Sell $1 /-$ mice Jackson Laboratory) to derive pmel-Ly5.1-double-Tg mice, pmel-Thy1.1-double-Tg mice, and pmel-1 CD62 $\mathrm{L}^{-/-}$mice, respectively. B16 $\left(\mathrm{H}-2^{\mathrm{b}}\right)$, a spontaneous gp $100^{+}$murine melanoma, was maintained in culture media (CM) (13). The gp 100- MCA-205 (National Cancer Institute Tumor Repository) was maintained in $\mathrm{CM}$ and used as irrelevant $\mathrm{H}-2^{\mathrm{b}}$ target.

Generation of BM chimeras. BM cells were obtained from femurs and tibias of $\beta_{2} \mathrm{~m}^{-/-}$and C57BL/6 mice (Taconic). Recipients were irradiated with $10 \mathrm{~Gy}$ and injected i.v. with $5 \times 10^{6} \mathrm{BM}$ cells. PBMC chimeras were analyzed at 8 weeks.

In vitro activation, cytokine release, and cytolytic assays. Pmel-1 splenocytes were isolated as described previously (13) and cultured in the presence of $1 \mu \mathrm{M}$ human gp100 $25-33$ (hgp 100 $25-33$ ) and CM containing $30 \mathrm{IU} / \mathrm{ml}$ of recombinant human IL-2 (rhIL-2) (Chiron Corp.) or $10 \mathrm{ng} / \mathrm{ml} \mathrm{rhIL-15}$ (PeproTech Inc.). Cells were restimulated weekly with $1 \mu \mathrm{M}$ hgp $100_{25-33^{-}}$ pulsed, irradiated splenocytes. Pmel-1 cells were frozen after each restimulation. Prior to adoptive transfer, pmel-1 lymphocytes were thawed and kept overnight in IL-2 culture medium at $37^{\circ} \mathrm{C}$. Cells were concurrently used for flow cytometry analysis, recognition, or cytolytic assays. When naive cells were used, pmel-1 splenocytes were depleted of non-CD8 ${ }^{+} \mathrm{T}$ cells using a MACS negative selection column (Miltenyi Biotec). CD62 $\mathrm{L}^{\text {high }}$ and $\mathrm{CD} 62 \mathrm{~L}^{\text {low }}$ populations were sorted the day before adoptive transfer using a MACS CD62L-positive selection column (Miltenyi Biotec). Cytokine release assays and cytolytic assays were performed as previously described (29).

Adoptive cell transfer, vaccination, and cytokine administration. Female C57BL/ 6 mice (Jackson Laboratory) at 6-12 weeks of age were injected s.c. with $2 \times 10^{5}$ to $5 \times 10^{5}$ B16 melanoma cells. Mice ( $n=5$ for all groups) 
were treated 10-14 days later with i.v. adoptive transfer of pmel-1 CD8 ${ }^{+} \mathrm{T}$ enriched splenocytes or in vitro activated splenocytes, as indicated. Lymphopenia was induced by sublethal irradiation ( $500 \mathrm{cGy}$ ) of tumor-bearing mice on the day of treatment. Mice were vaccinated with $2 \times 10^{7} \mathrm{PFU}$ of a previously described recombinant fowlpox virus expressing human gp100 (rFPhgp100; Therion Biologics) (53) and rhIL-2 at 600,000 IU (36 $\mu \mathrm{g}$ per dose) were administered by i.p. injection twice daily for a total of 6 doses. Calipers were used to measure tumors, and the products of the perpendicular diameters were recorded. All experiments were performed in a blinded, randomized fashion (the investigator who performed the measurements had no knowledge of the experimental group) and performed independently at least twice with similar results. All animal experiments were approved by the NCI Animal Ethics Committee of the NCI.

Enumeration of adoptively transferred cells. On the days indicated, mice were bled by tail vein into heparin-containing microcentrifuge tubes (Marsh Bio Products) and sacrificed. We harvested spleen and tumor and homogenized them into a single-cell suspension using the rubber end of a 3-cc syringe and a 40- $\mu \mathrm{M}$ filter cup. Samples were enumerated in our laboratory using trypan blue exclusion for splenocyte count, and in the NIH Clinical Laboratory for peripheral blood analysis, and were analyzed by flow cytometry for CD8 and V $\beta 13$, Ly5.1, or Thy. 1 expression by cells. We calculated the absolute number of pmel-1 cells/ $\mu$ l by multiplying the splenocyte count or ALC by the ratio $\mathrm{CD}^{+} \mathrm{V} \beta 13^{+} /$lymphocyte gate, $\mathrm{CD} 8^{+}$Ly $5.1^{+} /$lymphocyte gate, or $\mathrm{CD}^{+}$Thy $1.1^{+} /$lymphocyte gate.

In vitro CFSE proliferation assay. Pmel-1 cells were labeled with $1 \mu \mathrm{M}$ CFSE (Invitrogen Corp.) and restimulated with $1 \mu \mathrm{M}$ hgp $100_{25-33}$-pulsed, irradiated splenocytes in CM containing $30 \mathrm{UI} / \mathrm{ml}$ of rhIL-2. From day 1 to day 4 after restimulation, cells were harvested and analyzed by flow cytometry for CFSE, CD8, and V $\beta 13$ expression.

Flow cytometry and antibodies. All antibodies were purchased from BD Biosciences except goat polyclonal antibody against CCR7 (Abcam Inc.), donkey anti-goat-PE (Jackson ImmunoResearch Laboratories Inc.), KLRG-1-PE (2F1) (SouthernBiotech), and anti-human granzyme B-PE (GB11) (CALTAG Laboratories). Samples were analyzed using a FACSCalibur flow cytometer and CellQuest software (Becton Dickinson).

Detection of BID and BAD protein expression by Western blot analysis. Cells were lysed in RIPA buffer (Boston BioProducts Inc.) with $1 \mathrm{mM}$ of phenylmethylsulfonyl fluoride (Sigma-Aldrich). Then $10 \mu \mathrm{g}$ protein from each lysate was loaded to a well of a 12\% PAGE gel (PAGEgel Inc.) and run in reducing conditions for an hour. After transfer, the membrane was blocked with $10 \%$ nonfat milk in wash buffer containing $10 \mathrm{mM}$ Tris ( $\mathrm{pH}$ 7.5), $100 \mathrm{mM} \mathrm{NaCl}$ (Quality Biological Inc.), and $0.1 \%$ Tween-20 (Fisher Scientific) overnight. The membrane was incubated with $1 \mu \mathrm{g} / \mathrm{ml}$ rat anti-mouse BID (R\&D Systems), $0.5 \mu \mathrm{g} / \mathrm{ml}$ mouse anti-mouse BAD (BD Biosciences), and $0.3 \mu \mathrm{g} / \mathrm{ml}$ mouse anti-mouse GAPDH (Chemicon International) for 1 hour and subsequently washed 3 times. We used $1 \mu \mathrm{g} / \mathrm{ml}$ of HRP-conjugated anti-mouse Ig (Amersham Biosciences) or anti-rat IgG (SouthernBiotech) as secondary antibodies. The membrane was developed in SuperSignal West Pico Chemiluminescent Substrate (Pierce) and photographed by LAS-1000 luminescent image analyzer (FUJIFILM Medical Systems).

Microarray analysis. RNA was isolated from $\mathrm{CD}^{+}$-enriched pmel-1 cells after 1 and 2 stimulations using RNeasy columns (QIAGEN) and indirectly labeled via a single round of linear amplification with Amino Allyl MessageAmp reagents (Ambion). The labeled samples were combined and hybridized overnight to 22,000-gene oligonucleotide arrays supplied by the Laboratory of Molecular Technology (NCI). We obtained data image files using a GenePix 4000B scanner (Axon Instruments) and imported them into GeneSpring version 6.2 (Silicon Genetics).

Statistical analysis. Tumor graphs were compared using Wilcoxon rank sum test.

\section{Acknowledgments}

The authors would like to thank A. Mixon and S. Farid of the Flow Cytometry Unit (Surgery Branch of the NCI) for flow cytometry analysis and P.A. Antony, C.M. Paulos, C.S. Hinrichs, and A. Ranganathan for critical review of the manuscript.

Received for publication January 14, 2005, and accepted in revised form April 12, 2005.

Address correspondence to: Nicholas P. Restifo, National Cancer Institute, National Institutes of Health, Mark O. Hatfield Clinical Research Center, Room 3-5762, 10 Center Drive, Bethesda, Maryland 20892-1502, USA. Phone: (301) 496-4904; Fax: (301) 496-0011; E-mail: restifo@nih.gov.
1. Rosenberg, S.A., Yang, J.C., and Restifo, N.P. 2004. Cancer immunotherapy: moving beyond current vaccines. Nat. Med. 10:909-915.

2. Dudley, M.E., and Rosenberg, S.A. 2003. Adoptivecell-transfer therapy for the treatment of patients with cancer. Nat. Rev. Cancer. 3:666-675.

3. Childs, R.W., and Barrett, J. 2004. Nonmyeloablative allogeneic immunotherapy for solid tumors. Annu. Rev. Med. 55:459-475.

4. Dudley, M.E., et al. 2002. Cancer regression and autoimmunity in patients after clonal repopulation with antitumor lymphocytes. Science. 298:850-854.

5. Rosenberg, S.A., and Dudley, M.E. 2004. Cancer regression in patients with metastatic melanoma after the transfer of autologous antitumor lymphocytes. Proc. Natl. Acad. Sci. U. S. A. 101(Suppl. 2):14639-14645.

6. Sallusto, F., Geginat, J., and Lanzavecchia, A. 2004. Central memory and effector memory $\mathrm{T}$ cell subsets: function, generation, and maintenance. Annu. Rev. Immunol. 22:745-763.

7. Masopust, D., Kaech, S.M., Wherry, E.J., and Ahmed, R. 2004. The role of programming in memory T-cell development. Curr. Opin. Immunol. 16:217-225.

8. Appay, V., and Rowland-Jones, S.L. 2004. Lessons from the study of T-cell differentiation in persistent human virus infection. Semin. Immunol. 16:205-212.
9. Maus, M.V., et al. 2004. Extensive replicative capacity of human central memory T cells. J. Immunol. 172:6675-6683.

10. Yee, C., et al. 2002. Adoptive T cell therapy using antigen-specific CD8+ T cell clones for the treatment of patients with metastatic melanoma: in vivo persistence, migration, and antitumor effect of transferred T cells. Proc. Natl. Acad. Sci. U. S. A. 99:16168-16173.

11. Dudley, M.E., et al. 2001. Adoptive transfer of cloned melanoma-reactive T lymphocytes for the treatment of patients with metastatic melanoma. J. Immunother. 24:363-373.

12. Dudley, M.E., et al. 2002. A phase I study of nonmyeloablative chemotherapy and adoptive transfer of autologous tumor antigen-specific T lymphocytes in patients with metastatic melanoma. J. Immunother. 25:243-251.

13. Overwijk, W.W., et al. 2003. Tumor regression and autoimmunity after reversal of a functionally tolerant state of self-reactive CD8+ T cells. J. Exp. Med. 198:569-580.

14. Gold, J.S., et al. 2003. A single heteroclitic epitope determines cancer immunity after xenogeneic DNA immunization against a tumor differentiation antigen. J. Immunol. 170:5188-5194.

15. Turk, M.J., Guevara-Patino, J.A., Rizzuto, G.A., Engelhorn, M.E., and Houghton, A.N. 2004. Con- comitant tumor immunity to a poorly immunogenic melanoma is prevented by regulatory $\mathrm{T}$ cells. J. Exp. Med. 200:771-782.

16. Palmer, D.C., et al. 2004. Vaccine-stimulated, adoptively transferred CD8+ T cells traffic indiscriminately and ubiquitously while mediating specific tumor destruction. J. Immunol. 173:7209-7216.

17. Pearce, E.L., et al. 2003. Control of effector CD8+ $\mathrm{T}$ cell function by the transcription factor Eomesodermin. Science. 302:1041-1043.

18. Danial, N.N., and Korsmeyer, S.J. 2004. Cell death: critical control points. Cell. 116:205-219.

19. Hildeman, D.A., Mitchell, T., Kappler, J., and Marrack, P. 2003. T cell apoptosis and reactive oxygen species. J. Clin. Invest. 111:575-581. doi:10.1172/ JCI200318007.

20. Degli, E.M., et al. 2003. Post-translational modification of Bid has differential effects on its susceptibility to cleavage by caspase 8 or caspase 3. J. Biol. Chem. 278:15749-15757.

21. Voehringer, D., et al. 2001. Viral infections induce abundant numbers of senescent CD8 T cells. J. Immunol. 167:4838-4843.

22. Voehringer, D., Koschella, M., and Pircher, H. 2002. Lack of proliferative capacity of human effector and memory $T$ cells expressing killer cell lectinlike receptor G1 (KLRG1). Blood. 100:3698-3702.

23. Bertram, M.J., et al. 1999. Identification of a gene 
that reverses the immortal phenotype of a subset of cells and is a member of a novel family of transcription factor-like genes. Mol. Cell. Biol. 19:1479-1485.

24. Lanzavecchia, A., and Sallusto, F. 2002. Progressive differentiation and selection of the fittest in the immune response. Nat. Rev. Immunol. 2:982-987.

25. Von Andrian, U.H., and Mempel, T.R. 2003. Hom ing and cellular traffic in lymph nodes. Nat. Rev. Immunol. 3:867-878.

26. Weninger, W., Crowley, M.A., Manjunath, N., and Von Andrian, U.H. 2001. Migratory properties of naive, effector, and memory CD8(+) T cells. J. Exp. Med. 194:953-966.

27. Speiser, D.E., et al. 1997. Self antigens expressed by solid tumors do not efficiently stimulate naive or activated T cells: implications for immunotherapy. J. Exp. Med. 186:645-653.

28. Powell, D.J., Jr., Dudley, M.E., Robbins, P.F., and Rosenberg, S.A. 2005. Transition of late-stage effector T cells to CD27+ CD28+ tumor-reactive effector memory $\mathrm{T}$ cells in humans after adoptive cell transfer therapy. Blood. 105:241-250.

29. Klebanoff, C.A., et al. 2004. IL-15 enhances the in vivo antitumor activity of tumor-reactive CD8+ T cells. Proc. Natl. Acad. Sci. U. S. A. 101:1969-1974.

30. Manjunath, N., et al. 2001. Effector differentiation is not prerequisite for generation of memory cytotoxic T lymphocytes. J. Clin. Invest. 108:871-878. doi:10.1172/JCI200113296.

31. Wherry, E.J., et al. 2003. Lineage relationship and protective immunity of memory CD8 T cell subsets. Nat. Immunol. 4:225-234.

32. Kagamu, H., Touhalisky, J.E., Plautz, G.E., Krauss, J.C., and Shu, S. 1996. Isolation based on L-selectin expression of immune effector $\mathrm{T}$ cells derived from tumor-draining lymph nodes. Cancer Res. 56:4338-4342.

33. Hendriks, J., et al. 2000. CD27 is required for generation and long-term maintenance of $\mathrm{T}$ cell immunity. Nat. Immunol. 1:433-440.

34. Hendriks, J., Xiao, Y., and Borst, J. 2003. CD27 pro- motes survival of activated $T$ cells and complements CD28 in generation and establishment of the effector T cell pool. J. Exp. Med. 198:1369-1380.

35. Arens, R., et al. 2004. Tumor rejection induced by CD70-mediated quantitative and qualitative effects on effector CD8+ T cell formation. J. Exp. Med. 199:1595-1605.

36. Rowley, T.F., and Al Shamkhani, A. 2004. Stimulation by soluble CD70 promotes strong primary and secondary CD8+ cytotoxic $\mathrm{T}$ cell responses in vivo. J. Immunol. 172:6039-6046.

37. Liu, K., and Rosenberg, S.A. 2001. Transduction of an IL-2 gene into human melanoma-reactive lymphocytes results in their continued growth in the absence of exogenous IL-2 and maintenance of specific antitumor activity. J. Immunol. 167:6356-6365.

38. Antony, P.A., et al. 2005. CD8+ T cell immunity against a tumor/self-antigen is augmented by CD4+ T helper cells and hindered by naturally occurring $\mathrm{T}$ regulatory cells. J. Immunol. 174:2591-2601.

39. Schluns, K.S., Kieper, W.C., Jameson, S.C., and Lefrancois, L. 2000. Interleukin-7 mediates the homeostasis of naive and memory CD8 T cells in vivo. Nat. Immunol. 1:426-432.

40. Goldrath, A.W., et al. 2002. Cytokine requirements for acute and basal homeostatic proliferation of naive and memory CD8+ T cells. J. Exp. Med. 195:1515-1522.

41. Kaech, S.M., et al. 2003. Selective expression of the interleukin 7 receptor identifies effector CD8 T cells that give rise to long-lived memory cells. Nat. Immunol. 4:1191-1198.

42. Huster, K.M., et al. 2004. Selective expression of IL-7 receptor on memory $\mathrm{T}$ cells identifies early CD40L-dependent generation of distinct CD8+ memory T cell subsets. Proc. Natl. Acad. Sci. U. S. A. 101:5610-5615.

43. Tan, J.T., et al. 2002. Interleukin (IL)-15 and IL-7 jointly regulate homeostatic proliferation of memory phenotype CD8+ cells but are not required for memory phenotype CD4+ cells. J. Exp. Med. 195: $1523-1532$

44. Judge, A.D., Zhang, X., Fujii, H., Surh, C.D., and Sprent, J. 2002. Interleukin 15 controls both proliferation and survival of a subset of memory-phenotype CD8(+) T cells. J. Exp. Med. 196:935-946.

45. Tuma, R.A., and Pamer, E.G. 2002. Homeostasis of naive, effector and memory CD8 T cells. Curr. Opin. Immunol. 14:348-353.

46. Dubois, S., Mariner, J., Waldmann, T.A., and Tagaya, Y. 2002. IL-15Ralpha recycles and presents IL-15 in trans to neighboring cells. Immunity. 17:537-547.

47. Schluns, K.S., Klonowski, K.D., and Lefrancois, L. 2004. Transregulation of memory CD8 T-cell proliferation by IL-15R $\{$ alpha\}+ bone marrow-derived cells. Blood. 103:988-994.

48. Robbins, P.F., et al. 2004. Cutting edge: persistence of transferred lymphocyte clonotypes correlates with cancer regression in patients receiving cell transfer therapy. J. Immunol. 173:7125-7130.

49. Papagno, L., et al. 2004. Immune activation and CD8(+) T-cell differentiation towards senescence in HIV-1 infection. PLoS Biol. 2:E20. doi:10.1371/ journal.pbio.0020020.

50. Heintel, T., et al. 2002. The fraction of perforinexpressing HIV-specific CD8 T cells is a marker for disease progression in HIV infection. AIDS. 16:1497-1501.

51. Migueles, S.A., et al. 2002. HIV-specific CD8+ T cell proliferation is coupled to perforin expression and is maintained in nonprogressors. Nat. Immunol. 3:1061-1068

52. Walter, E.A., et al. 1995. Reconstitution of cellular immunity against cytomegalovirus in recipients of allogeneic bone marrow by transfer of T-cell clones from the donor. N. Engl. J. Med. 333:1038-1044.

53. Overwijk, W.W., et al. 1998. gp100/pmel 17 is a murine tumor rejection antigen: induction of "self"-reactive, tumoricidal T cells using highaffinity, altered peptide ligand. J. Exp. Med. 188:277-286 